\title{
A real-time $P C R$ assay with improved specificity for detection and discrimination of all clinically relevant Bordetella species by the presence and distribution of three Insertion Sequence elements
}

\author{
Lieuwe Roorda', Johannes Buitenwerf ${ }^{1}$, Jacobus M Ossewaarde ${ }^{1,2}$, Anneke van der Zee ${ }^{1 *}$
}

\begin{abstract}
Background: In Dutch laboratories molecular detection of B. pertussis and B. parapertussis is commonly based on insertion sequences IS481 and IS1001, respectively. Both IS elements are more widely spread among Bordetella species. Both Bordetella holmesii, and B. bronchiseptica can harbour IS481. Also, IS1001 is found among B. bronchiseptica. IS481, and IS1001 based PCR thus lacks specificity when used for detection of specific Bordetella spp.

Findings: We designed a PCR based on IS1002, another IS element that is present among Bordetella species, and exploited it as a template in combination with PCR for IS481, and IS1001. In combining the PCRs for IS481, IS1001, and 151002 , and including an inhibition control, we were able to detect and discriminate all clinically relevant Bordetella species.
\end{abstract}

Conclusions: We developed an improved PCR method for specific detection of B. pertussis, B. parapertussis, B. holmesii, and B. bronchiseptica.

\section{Background}

The genus Bordetella is comprised of 8 species, 4 of which are known to infect humans; B. pertussis, B. parapertussis, $B$. holmesii, and B. bronchiseptica. The most important cause for whooping cough is $B$. pertussis, followed by B. parapertussis. Bordetella holmesii was first described in 1995 [1], and has since been isolated from patients with a serious underlying disease [2-5]. B. bronchiseptica is usually restricted to animals but occasionally is isolated from immunocompromised patients [6,7].

A large number of PCR (polymerase chain reaction) assays have been described for detection of Bordetella pertussis and $B$. parapertussis, and more recently $B$. holmesii [8-14]. Most PCRs are based on detection of the insertion sequence elements IS481, and IS1001, because they exist in multiple copies in the chromosome. A high copy number of PCR target, contributes to the sensitivity of detection. IS481 (1053 bp) shows a high degree of

\footnotetext{
* Correspondence: zeea@maasstadziekenhuis.nl

'Maasstad Laboratory, Molecular Diagnostics Unit, Maasstad Hospital,

Olympiaweg 350, 3078HT Rotterdam, The Netherlands

Full list of author information is available at the end of the article
}

homology between different members of Bordetella species of $96 \%$. All IS1001 (1306 bp) sequences known in Genbank are 100\% homologues, as is IS1002 (1040 bp). The degree of homology between IS481, IS1001, and IS1002 is less than $5 \%$.

The insertion sequences (IS) that are present in Bordetella spp., are distributed according to species and/or host specificity. For example, IS1001 is found in all B. parapertussis, but IS1002 is found only in B. parapertussis that infect humans and is absent from $B$. parapertussis sheep isolates [15]. B. pertussis harbors both IS481 and IS 1002 while some $B$. bronchiseptica strains may have either IS481 or IS1001 [15]. B. holmesii only has IS481.

Due to the distribution of IS481, and IS1001, PCRs for B. pertussis and B. parapertussis lack specificity [16]. In recent years many newly developed PCRs were introduced with improved specificity but often with a compromise to sensitivity $[11,13,14]$.

The aim of this study was to improve the specificity of PCR by including another IS element, IS1002, as target in PCR. IS1002, in addition to IS481, and IS1001, which 
enables discrimination of $B$. pertussis, B. holmesii, $B$. parapertussis, and B. bronchiseptica.

\section{Methods}

IS1002 has not been exploited before as a template in PCR detection. We developed a specific IS1002 PCR (Table 1) to improve our ability to recognize the correct Bordetella species, and to combine it with IS481, and IS1001 specific PCRs. Addition of Phocine Herpes Virus (PhHV) as internal control acts to monitor the extraction as well as the efficiency of amplification [17].

We investigated standard laboratory strains of Bordetella (kindly provided by Dr. Frits Mooi and Kees Heuvelman, Laboratory for Vaccine Preventable Diseases, National Institute of Public Health and the Environment, Bilthoven, The Netherlands), which are shown in Table 2. Since detection of B. pertussis is of highest concern, we investigated the performance of the newly developed PCR on 100 clinical samples that were previously positive. To verify the specificity of the PCR we investigated 20 clinical respiratory tract samples that were suspect for other pathogens than Bordetella. Prior to PCR, laboratory strains were diluted and boiled to release DNA (equivalent to approximately 5 cells/ $\mu \mathrm{l}$ ). Clinical samples were extracted using EasyMAG (Biomerieux, Grenoble, France).

PCRs for detection of IS481, IS1001, and IS1002 were performed in a reaction mixture of $25 \mu \mathrm{l}$ containing 0.5 $\mu \mathrm{M}$ of $I S 481$ and $I S 1001$ primers, $0.8 \mu \mathrm{M}$ and $0.6 \mu \mathrm{M}$ of IS1002 Forward and Reverse primer, respectively, and $0.2 \mu \mathrm{M}$ of PhHV primers. Probes (Table 1) were added with concentrations of $0.14,0.14,0.16$, and $0.08 \mu \mathrm{M}$ for respectively $I S 481, I S 1001, I S 1002$, and the internal control in PCR reaction mix (Sigma -Aldrich (E3004), Munich, Germany). Nine $\mu$ l of template DNA was

\begin{tabular}{|c|c|c|}
\hline Template & $\begin{array}{l}\text { Primer/probe } \\
\text { (label) }\end{array}$ & Sequence $\left(5^{\prime}-3^{\prime}\right)$ \\
\hline \multirow[t]{3}{*}{ IS481 } & Forward primer & GCCGGATGAACACCCATAAG \\
\hline & Reverse primer & GCGATCAATTGCTGGACCAT \\
\hline & Probe (FAM) & CGATTGACCTTCCTACGTC-MGB \\
\hline \multirow[t]{3}{*}{ IS1001 } & Forward primer & AATTGCTGCAAGCCAACCA \\
\hline & Reverse primer & CCAGAGCCGTTTGAGTTCGT \\
\hline & Probe $(\mathrm{VIC})$ & ACATAGACCGTCAGCAG-MGB \\
\hline \multirow[t]{3}{*}{ IS1002 } & Forward primer & CTAGGTCGAGCCCTTCTTGTTAAC \\
\hline & Reverse primer & GCGGGCAAGCCACTTGTA \\
\hline & Probe $(\mathrm{CY} 5)$ & $\begin{array}{l}\text { CATCGTCCAGTTCTGTTGCATCACCC- } \\
\text { BBQ }\end{array}$ \\
\hline \multirow[t]{3}{*}{ PhHV } & Forward primer & GGGCGAATCACAGATTGAATC \\
\hline & Reverse primer & GCGGTTCCAAACGTACCAA \\
\hline & Probe (NED) & TIITATGTGTCCGCCACCA-MGB \\
\hline
\end{tabular}

Table 2 Results of PCRs for detection of IS481, IS1001, and IS1002, and the interpretation for identification of clinically relevant Bordetella species

\begin{tabular}{|c|c|c|c|c|}
\hline $\begin{array}{l}\text { Bordetella } \\
\text { subspecies* }\end{array}$ & IS481 & IS1001 & IS1002 & identification \\
\hline pertussis & + & - & + & B. pertussis \\
\hline parapertussis & - & + & + & B. parapertussis \\
\hline holmesii & + & - & - & $\begin{array}{l}\text { B. holmesii/B. } \\
\text { bronchiseptica }\end{array}$ \\
\hline bronchiseptica & - & + & - & B. bronchiseptica \\
\hline petrii & - & - & - & $\begin{array}{l}\text { identification not } \\
\text { possible }\end{array}$ \\
\hline hinzii & - & - & - & $\begin{array}{l}\text { identification not } \\
\text { possible }\end{array}$ \\
\hline
\end{tabular}

*Strains were kindly provided by Dr. Frits Mooi and Kees Heuvelman, Laboratory for Vaccine Preventable Diseases, National Institute of Public Health and the Environment, Bilthoven, The Netherlands.

added. Amplification was carried out on an ABI 7500 Real-Time PCR system (Applied Biosystems (ABI), Nieuwerkerk a/d IJsel, The Netherlands). The temperature profile included initial denaturation of $4 \mathrm{~min}$. at $94^{\circ} \mathrm{C}$, followed by 50 cycles of $94^{\circ} \mathrm{C}$ for 15 sec., and $60^{\circ} \mathrm{C}$ for $1 \mathrm{~min}$. Cycle treshold $(\mathrm{Ct})$ values were determined automatically using the ABI SDS software.

\section{Results}

\section{Evaluation of sensitivity}

In order to evaluate the performance of the combination of all four PCRs in a multiplex format performed on standard laboratory strains (Table 2): IS481, IS1001, IS1002, and the internal control, we compared Ct values to each single PCR. No significant differences were found (not shown). Since IS481 is present with a much higher copy number in B. pertussis than IS1002 (approximately 200 and 10 copies, respectively), Ct values of IS481 were on average 3.7 lower compared to $\mathrm{Ct}$ values of $I S 1002$ detection. Of a $10 \mathrm{CFU} / \mathrm{ml}$ dilution of B. pertussis cells both IS481 and IS1002 were positive with $\mathrm{Ct}$ values of respectively 30.6 and 34.4. The sensitivity of $B$. parapertussis detection was comparable with that using only IS1001 as target.

\section{Evaluation of specificity}

To evaluate the specificity of each IS-based PCR, laboratory strains of most known Bordetella species (with exception of $B$. avium and B. trematum; Table 2), were subjected to the IS-based PCRs. Results were as was expected (Table 2).

To investigate whether all targets were amplified with high fidelity, and would not confound the specificity of detection, we made serial dilutions and subjected these to PCR. With limiting concentrations of B. pertussis bacteria, detection of IS1002 is lost before detection of $I S 481$, because of the difference in copy number. 
To ensure specificity and to assess a cut-off Ct value for $B$. pertussis, 100 previously positive clinical samples were subjected to PCR. Only when Ct values of IS481 $>37$, IS 1002 was negative ( $2 \%$ of 100 samples). Thus, a cut-off of Ct 35 should be taken for IS481. In 20 respiratory tract samples suspect for other pathogens, no Bordetella positives were found. With $B$. parapertussis PCR detection, similar Ct values of IS1001 and IS1002 were found, and hence no cut-off $\mathrm{Ct}$ values are necessary for IS1001, and IS1002.

\section{Quality assessment}

In addition, the multiplex IS-based PCR was evaluated using the External Quality Assessment Programme of Bordetella pertussis from the Quality Control for Molecular Diagnostics (QCMD, Glasgow, UK). The QCMD panel of samples consisted of $5 \mathrm{~B}$. pertussis in a range of concentrations, $1 \mathrm{~B}$. parapertussis, $1 \mathrm{~B}$. holmesii, $2 \mathrm{~B}$. bronchiseptica, $1 \mathrm{~B}$. hinzii, 1 Haemophilus influenza, and 1 negative sample. Using our newly developed PCR we correctly identified $B$. pertussis even in the lowest concentration of $10 \mathrm{CFU} / \mathrm{ml}$, and $B$. parapertussis. $B$. holmesii and one IS481 containing B. bronchiseptica were recognized correctly and not as B. pertussis. Haemophilus influenza did not cross react with any of the targeted IS elements.

\section{Discussion}

In this study we included IS1002 as target in PCR based detection of Bordetella, in addition to IS481 and IS1001, which is the commonly used PCR in The Netherlands. We aimed to improve the specificity of PCR because the addition of IS1002 enables the discrimination of B. pertussis, B. parapertussis, B. holmesii, and B. bronchiseptica.

In the final report of QCMD (Pierard, D., O. Soetens, and G. Ieven. Bordetella pertussis (BPDNA09) EQA Pilot Study. February 2010. QCMD, Glasgow UK.), a high degree of false positivity was observed for detection of $B$. pertussis. It appeared that more than $80 \%$ of laboratories contributing to the study used a PCR that is based on IS481 and this accounts for the large proportion of false positive results. Indeed, IS481 positive samples could either be positive for B. pertussis, B. holmesii, or $B$. bronchiseptica. Here, we have shown that in our PCR assay these organisms can be discriminated from one another. There are however some limitations. In a previous study [15] it was shown that IS481 is very rarely found among B. bronchiseptica (1\% of strains), in contrast to IS1001 that was found in approximately 50\% of the studied strain collection. Consequently, approximately $50 \%$ of $B$. bronchiseptica carry no known IS elements and thus cannot be detected by IS-based PCR. B. bronchiseptica strains that contain a copy of IS481 cannot be discriminated from B. holmesii using IS-based PCRs. If PCR presents a single IS481 positive signal, one might re-investigate the sample using the $B$. holmesii specific PCR targeting the recA gene that was described earlier [18] to discriminate from B. bronchiseptica.

The performance of our assay may fail if clinical samples might contain more than one Bordetella species. However, after more than 15 years of experience with PCR detection of B. pertussis (IS481) and B. parapertussis (IS1001), we did not find more than one Bordetella species present in clinical specimens.

During the evaluation, we sometimes observed a weak positive signal for IS481 (Ct > 37) from B. hinzii, although high concentrations of this organism were negative in PCR. This may indicate that $B$. hinzii might contain an IS481-like sequence that does not exactly match our PCR. As B. hinzii is solely confined to birds, this finding will not confound PCR based on IS481, IS1001 and IS1002 for detection and discrimination of the clinically relevant Bordetella species.

\section{Conclusions}

In conclusion, we have developed a real time PCR with improved specificity for detection and discrimination of all clinically relevant Bordetella species.

\section{Acknowledgements}

Bordetella strains were kindly provided by Dr Frits Mooi and Kees

Heuvelman, Laboratory for Vaccine Preventable Diseases, National Institute of Public Health and the Environment, Bilthoven, The Netherlands.

We thank Quality Control for Molecular Diagnostics, Glasgow, UK, for using their data.

\section{Author details}

'Maasstad Laboratory, Molecular Diagnostics Unit, Maasstad Hospital, Olympiaweg 350, 3078HT Rotterdam, The Netherlands. 'Department of Medical Microbiology and Infectious Diseases, Erasmus MC, Rotterdam, The Netherlands.

\section{Authors' contributions}

LR carried out the molecular genetic studies, participated in the design of PCR and drafted the manuscript. JB and JMO participated in coordination of the study and helped to draft the manuscript. AZ conceived of the study, and participated in the design. All authors read and approved the final manuscript.

\section{Competing interests}

The author(s) declare that they have no competing interests.

Received: 27 August 2010 Accepted: 21 January 2011 Published: 21 January 2011

\section{References}

1. Weyant RS, Hollis DG, Weaver RE, .Amin MF, Steigerwalt AG, O'Connor SP, Whitney AM, Daneshvar MI, Moss CW, Brenner DJ: Bordetella holmesii sp. nov., a new gram-negative species associated with septicemia. J Clin Microbiol 1995, 33(1):1-7.

2. Dörbecker C, Licht C, Körber F, Plum G, Haefs C, Hoppe B, Seifert H: Community-acquired pneumonia due to Bordetella holmesii in a patient with frequently relapsing nephrotic syndrome. J Infect 2007, 54(4):e203-5.

3. Greig JR, Gunda SS, Kwan JTC: Bordetella holmesii bacteraemia in an individual on haemodialysis. Scand J Infect Dis 2001, 33(9):716-7. 
4. McCavit TL, Grube $\mathrm{S}$, Revell $\mathrm{P}$, Quinn $\mathrm{CT}$ : Bordetella holmesii bacteremia in sickle cell disease. Pediatr Blood Cancer 2008, 51(6):814-6.

5. Shepard CW, Daneshvar MI, Kaiser RM, Ashford DA, Lonsway D, Patel JB, Morey RE, Jordan JG, Weyant RS, Fischer M: Bordetella holmesii bacteremia: a newly recognized clinical entity among asplenic patients. Clin Infect Dis 2004, 38(6):799-804.

6. Won KB, Ha GY, Kim JS, Kang HJ, Tak WT, Lee JH: Relapsing Peritonitis Caused by Bordetella bronchiseptica in Continuous Ambulatory Peritoneal Dialysis Patient: A Case Report. J Korean Med Sci 2009, 24(Suppl):S215-8.

7. Woolfrey BF, Moody JA: Human Infections associated with Bordetella bronchiseptica. Clin Microbiol Rev 4:243-255.

8. Guthrie JL, Robertson AV, Tang P, Jamieson F, Drews SJ: Novel duplex realtime PCR assay detects Bordetella holmesii in specimens from patients with Pertussis-like symptoms in Ontario, Canada. J Clin Microbiol 2010, 48(4):1435-7.

9. Knorr L, Fox JD, Tilley PA, Ahmed-Bentley J: Evaluation of real-time PCR for diagnosis of Bordetella pertussis infection. BMC Infect Dis 2006, 23(6):62.

10. Poddar SK: Detection and discrimination of $B$ pertussis and $B$ holmesii by real-time PCR targeting IS481 using a beacon probe and probe-target melting analysis. Mol Cell Probes 2003, 17(2-3):91-8.

11. Probert WS, Ely J, Schrader K, Atwell J, Nossoff A, Kwan S: Identification and Evaluation of New Target Sequences for Specific Detection of Bordetella pertussis by Real-Time PCR. J Clin Microbiol 2008, 46(10):103228-3231.

12. Reischl U, Lehn N, Sanden GN, Loeffelholz MJ: Real-time PCR assay targeting IS481 of Bordetella pertussis and molecular basis for detecting Bordetella holmesii. J Clin Microbiol 2001, 39(5):1963-6.

13. Tatti KM, Wu KH, Tondella ML, Cassiday PK, Cortese MM, Wilkins PP, Sanden GN: Development and evaluation of dual-target real-time polymerase chain reaction assays to detect Bordetella spp. Diagn Microbiol Infect Dis 2008, 61(3):264-72.

14. Van der Zee A, Mooi FR, van Embden J, Musser JM: Molecular Evolution and Host Adaptation of Bordetella spp.Phylogenetic Analysis Using Multilocus Enzyme Electrophoresis and Typing with Three Insertion Sequences. J Bacteriol 1997, 179(21):6609-6617.

15. Vielemeyer O, Crouch JY, Edberg SC, Howe JG: Identification of Bordetella pertussis in a Critically III Human Immunodeficiency Virus-Infected Patient by Direct Genotypical Analysis of Gram-Stained Material and Discrimination from B. holmesii by Using a Unique recA Gene Restriction Enzyme Site. J Clin Microbiol 2004, 42(2):847-849.

16. Muyldermans $G$, Soetens $O$, Antoine M, Bruisten S, Vincart B, DoucetPopulaire F, Fry NK, Olcén P, Scheftel JM, Senterre JM, van der Zee A, Riffelmann M, Piérard D, Lauwers S: External quality assessment for molecular detection of Bordetella pertussis in European laboratories. J Clin Microbiol 2005, 43(1):30-5.

17. Niesters HG: Quantititation of viral load using real-time amplification techniques. Methods 25:419-429.

18. Antila M, He Q, de Jong C, Aarts I, Verbakel H, Bruisten S, Keller S, Haanperä M, Mäkinen J, Eerola E, Viljanen MK, Mertsola J, van der Zee A: Bordetella holmesii DNA is not detected in nasopharyngeal swabs from Finnish and Dutch patients with suspected pertussis. J Med Microbiol 2006, 55:1043-51.

doi:10.1186/1756-0500-4-11

Cite this article as: Roorda et al:: A real-time PCR assay with improved specificity for detection and discrimination of all clinically relevant Bordetella species by the presence and distribution of three Insertion Sequence elements. BMC Research Notes 2011 4:11.

\section{Submit your next manuscript to BioMed Central and take full advantage of:}

- Convenient online submission

- Thorough peer review

- No space constraints or color figure charges

- Immediate publication on acceptance

- Inclusion in PubMed, CAS, Scopus and Google Scholar

- Research which is freely available for redistribution

Submit your manuscript at www.biomedcentral.com/submit
Biomed Central 